\title{
PENGARUH KOMUNIKASI DAN CITRA MEREK TERHADAP LOYALITAS MEREK DENGAN KEPERCAYAAN SEBAGAI MEDIASI
}

\author{
Mauwelles Tamindael dan Tommy Setiawan Ruslim \\ Universitas Tarumanagara, Jakarta \\ Email : Mauwelles.115160299@stu.untar.ac.id
}

\begin{abstract}
This research purposed to determine the effect of brand communication and brand image to brand loyalty of H\&M's customer in Jakarta with brand trust as a mediator. The total samples of this research are 100 respondents who asked to respond the statements in the questionnaires on google form. The Data in this research were analyze with PLS-SEM. The result of this research shows that all variables have a positive and significant effect except, brand communication to brand loyalty with brand trust as a mediator which has a positive but not significant effect of H\&M's customer in Jakarta. This research can be used as a measurement of variables that affect brand loyalty of H\&M's customer.
\end{abstract}

Keywords: Communication, Image, Trust, Loyalty.

\begin{abstract}
Abstrak: Penelitian ini bertujuan untuk mengetahui pengaruh komunikasi merek dan citra merek terhadap loyalitas merek pada konsumen H\&M di Jakarta, dengan kepercayaan merek sebagai mediasi. Penelitian ini menggunakan sampel sebanyak 100 orang untuk menanggapi pernyataan kuesioner yang disebarkan dalam bentuk google form. Data pada penelitian ini diolah dengan metode PLS-SEM. Hasil pengolahan data menunjukkan bahwa seluruh variabel memiliki pengaruh positif dan signifikan kecuali, komunikasi merek terhadap loyalitas merek melalui kepercayaan merek sebagai mediasi yang memiliki pengaruh positif namun tidak signifikan pada konsumen H\&M di Jakarta. Penelitian ini dapat digunakan sebagai ukuran variabel-variabel yang mempengaruhi loyalitas pada konsumen H\&M.
\end{abstract}

Kata kunci: Komunikasi, Citra , Kepercayaan, Loyalitas.

\section{LATAR BELAKANG}

Persaingan yang ketat dengan perubahan gaya beli konsumen beralih ke e-commerce membuat perusahaan H\&M mengalami penurunan profit. Pada bursa saham Stockholm, perusahaan H\&M mengalami penurunan profit $62 \%$ dalam tiga bulan terakhir pada akhir febuari 2018. Ini menjelaskan penurunan terendah sejak 2005 lalu. Hal tersebut membuat perusahaan $\mathrm{H} \& \mathrm{M}$ harus mampu bertahan di tengah meluasnya penjualan online, sekaligus menunjukan pentingnya kesetiaan konsumen bagi kelangsungan hidup perusahaan. Menurut penelitian dari Grace \& O'cass (2005) menyatakan bahwa dalam mengkomunikasikan merek, terciptanya citra merek yang positif di benak target konsumen, sehingga dapat meningkatkan pemahaman dan harapan baru akan merek. Menurut penelitian Alhaddad (2015) menyatakan bahwa citra merek dapat menjadi dasar untuk menciptakan kesadaran dan keputusan pembelian pada konsumen yang kemudian hal tersebut dapat mempengaruhi kepercayaan konsumen. Kepercayaan konsumen yang dipengaruhi oleh citra merek dapat menciptakan kesetiaan terhadap merek itu sendiri. Oleh karena itu, penelitian ini bertujuan untuk mencari tahu pengaruh komunikasi merek dan citra merek terhadap loyalitas merek konsumen H\&M di Jakarta melalui kepercayaan merek sebagai mediasi. 


\section{KAJIAN TEORI}

Kajian teori mengikuti Teori Perilaku yang Direncanakan yang dilakukan oleh Azjen (1991) dimana teori ini menjelaskan niat dan tingkah laku mempengaruhi suatu perilaku manusia dalam merencanakan serta mengambil suatu keputusan. Theory of Planned Behavior (TPB) didasarkan pada asumsi bahwa manusia biasanya akan bertingkah laku sesuai dengan pertimbangan akal sehat dan mengambil informasi yang ada mengenai tingkah laku yang tersedia secara implisit atau eksplisit dalam mempertimbangkan akibat dari tingkah laku tersebut. Menurut Azjen (1991) manusia merupakan makhluk rasional yang akan memperhitungkan implikasi dari tindakan mereka sebelum mereka melakukan suatu perilaku yang akan mereka lakukan. Sikap dapat mempengaruhi suatu perilaku pada seseorang, keputusan perilaku untuk tertarik secara sadar akan suatu produk melalui komunikasi dan citra merek yang kemudian sikap perilaku memiliki kontrol dan keyakinan akan percaya dan menjadi setia.

\section{Komunikasi Merek}

Menurut Zehir et al. (2011) komunikasi merek merupakan suatu kunci dalam memasarkan suatu merek secara terintegrasi dengan mengkomunikasikan apa yang diinginkan dan dibutuhkan oleh konsumen. Menurut Sahin et al. (2011) menjelaskan bahwa komunikasi merek dilakukan untuk menciptakan pengakuan atas merek dibenak konsumen dan digunakan untuk membangun reputasi yang baik serta mempertahankan komitmen yang telah didapatkan oleh konsumen yang kemudian konsumen akan melakukan pembelian di masa yang akan datang. Menurut Chinomona (2016) komunikasi merek merupakan peran penting yang dilakukan perusahaan untuk mengkomunikasikan suatu merek dan diharapkan dapat menciptakan komitmen pada konsumen tersebut yang kemudian akan meneruskan pembeliannya di masa mendatang karena kesetiann konsumen kepada sebuah produk

\section{Citra Merek}

Menurut Salinas \& Perez (2009) citra merek didefinisikan sebagai gambaran suatu merek tentang penawaran yang berasosiasi terhadap produk tersebut secara spesifik dengan melibatkan konsumen sebagai gambaran merek itu sendiri. Low \& Lamb (2000) menjelaskan bahwa citra merek merupakan suatu persepsi dan emosi yang dilekatkan pada konsumen sebagai cara untuk menciptakan citra yang positif pada merek tersebut dan sebagai representasi citra merek di benak konsumen. Cretu \& Brodie (2007) menjelaskan bahwa citra merek merupakan bentuk representasi merek dibenak konsumen terkait suatu penawaran dan persepsi tentang suatu merek yang akan dibentuk pada konsumen.

\section{Kepercayaan Merek}

Menurut Delgado et al. (2001) kepercayaan merek merupakan usaha yang dilakukan untuk dapat dipercaya dan meyakinkan konsumen bahwa produk tersebut mampu memenuhi nilai yang dijanjikan sehingga dapat memenuhi intensi baik konsumen. Menurut Kotler (2003) kepercayaan merek adalah kemauan konsumen mempercayai merek dengan segala resikonya, karena ada harapan bahwa merek tersebut dapat memberikan hasil positif baginya. Menurut Chinomona (2016) kepercayaan merek merupakan faktor penting dalam usaha untuk dapat diandalkan dan dipercayakan secara bertanggungjawab untuk menjaga nilai dari suatu merek tersebut serta menawab kebutuhan konsumen

\section{Loyalitas Merek}


Zehir et al. (2011) menyatakan bahwa loyalitas merek merupakan pilihan yang dilakukan konsumen untuk membeli merek tertentu dibandingkan merek lain dalam satu kategori produk. Sebagaimana dimaksud dengan menjaga komitmen pada konsumen dengan tujuan agar konsumen melakukan pembelian kembali dimasa yang akan datang. Menurut Ballester dan Aleman (2001) loyalitas merek merupakan cara konsumen dalam menunjukan kepuasannya terhadap performa produk atau jasa yang di terima. Sumarwan (2011) menjelaskan bahwa loyalitas merek diartikan sebagai sikap positif seorang konsumen terhadap suatu merek, konsumen memiliki keinginan kuat untuk membeli ulang merek yang sama pada saat sekarang maupun masa yang akan datang. Keinginan yang kuat tersebut dibuktikan dengan selalu membeli merek yang sama

\section{Kaitan antara Variabel}

\section{Kaitan antara Komunikasi Merek terhadap Citra Merek}

Menurut Toha Jessica (2016) yang meneliti tentang pengaruh komunikasi merek dan citra merek terhadap kepercayaan merek menunjukkan bahwa pengaruh komunikasi merek terhadap citra merek menghasilkan koefisien path sebesar 0,674 dengan $t$-statistic sebesar $12.272>1,64$. Data penelitian ini dilakukan dengan menyebarkan kuisioner sebanyak 100 retailer yang menjual semen Tiga Roda di Jawa Timur. Menurut Ramadhani \& Widodo (2019) yang meneliti tentang pengaruh komunikasi merek terhadap citra merek membuktikan bahwa hubungan antara komunikasi merek dan citra merek memiliki T-value sebesar 11.43 dengan koefisien regresi sebesar 0.90 yang mana menunjukan hubungan positif dan signifikan antara komunikasi merek dengan citra merek pada konsumen Lenovo mahasiswa Telkom University di Kota Bandung. Menurut Ahsan (2019) yang meneliti tentang dimensi komunikasi merek, citra merek, kepercayaan merek dan loyalitas merek menunjukkan bahwa pengaruh brand communication terhadap brand image menghasilkan p-values $0.000<0.05$ dengan $t$-statistic $=4.415$. Ini sekaligus membuktikan bahwa terdapat hubungan yang positif dan signifikan antara brand communication dan brand image.

\section{Kaitan antara Komunikasi Merek terhadap Kepercayaan Merek}

Menurut Zehir et al. (2011) yang meneliti tentang pengaruh komunikasi merek terhadap kepercayaan merek menunjukkan bahwa terdapat pengaruh dari komunikasi merek terhadap kepercayaan merek. Hasil analisis regresi menunjukan bahwa brand communication berpengaruh positif dan signifikan terhadap brand trust dengan $\mathrm{p}<0.05 ; \beta=0.092$. Menurut Wuri Arenggoasih (2016) yang meneliti tentang pengaruh komunikasi merek terhadap kepercayaan merek menunjukkan bahwa terdapat pengaruh variabel brand communication terhadap variabel brand trust memiliki besar koefisien 0.778 dengan $t=24,676>1.96$ dan signifikan $=0.000$. Ini berarti menunjukan adanya hubungan positif dan signifikan antara brand communication dengan brand trust pada pemilih partai politik Gerindra. Menurut Reza Agung Revanto (2016) yang meneliti tentang pengaruh komunikasi merek terhadap kepercayaan merek menunjukkan bahwa terdapat pengaruh positif dan signifikan dari brand communication terhadap brand trust. Hasil penelitian ini menunjukan bahwa koefisien regresi untuk brand communication sebesar 0.546 dan positif terhadap brand trust pelanggan Smartfren di wilayah Surabaya.

\section{Kaitan antara Citra Merek terhadap Kepercayaan Merek}

Menurut Wissy Sayekti et al. (2019) menunjukkan hasil bahwa citra merek memiliki dampak positif dan signifikan terhadap kepercayaan merek dengan $T$-values $=4.84$ pada 95 responden di Tanggerang yang berusia 25 hingga 45 tahun dengan analisis SEM. Menurut 
Abdullah Alhaddad (2015) menyatakan hasil bahwa citra merek memiliki pengaruh positif dan signifikan terhadap kepercayaan merek dengan $T$-values $=13.924$ dan koefisien $\beta=0.60$ pada data 473 siswa dari Institut Administrasi Bisnis (HIBA). Wati Susilawati \& Wufron (2017) dalam penelitiannya menunjukkan bahwa citra merek berpengaruh positif dan signifikan terhadap kepercayaan merek pada produk dodol PT Herlinah Cipta Pratama.

\section{Kaitan antara Kepercayaan Merek terhadap Loyalitas Merek}

Menurut Zehir et al. (2011) dalam penelitiannya brand trust memiliki kontribusi terhadap sikap brand loyalty seorang konsumen karena merek yang terpercaya akan memiliki tingkat pembelian yang cenderung tinggi. Hasil analisis regresi menunjukkan bahwa brand trust memiliki pengaruh yang positif dan signifikan terhadap brand loyalty dengan $\mathrm{p}<0.01$; $\beta=0.550$. Menurut Ahmed (2014) dalam penelitiannya brand trust memiliki pengaruh yang positif dan signifikan terhadap brand loyalty. Hasil analisis regresi menunjukkan bahwa brand trust memiliki pengaruh yang positif dan signifikan terhadap brand loyalty dengan $\mathrm{p}<0.01 ; \beta=0.510$. Menurut Pertiwi et al. (2017) menunjukan hasil penelitiannya bahwa brand trust memiliki pengaruh positif dan signifikan terhadap brand loyalty. Brand trust mempengaruhi brand loyalty dengan koefisien sebesar 0.575 atau $57.5 \%$ dan $t$-value sebesar 6.624 .

\section{Kaitan antara Brand Communication terhadap Brand Loyalty dengan Brand Trust sebagai Mediasi}

Menurut Rika et al. (2019) dalam penelitiannya menunjukan pengaruh komunikasi merek terhadap loyalitas merek yang dimediasi oleh kepercayaan merek memiliki hasil yang positif. Berdasarkan penilaian uji sobel pada analisis regresi linier berganda diketahui bahwa nilai t hitung $(3,44)>(1,66) \mathrm{t}$ tabel dengan p-value $0,000<0,005$. Menurut Wuri Arenggoasih (2019) dalam penelitiannya menunjukan hasil yang positif dan signifikan antara brand communication terhadap brand loyalty yang dimediasi dengan brand trust pada pada pemilih partai politik Gerindra. Menurut Chinomona (2016) menyatakan bahwa komunikasi merek tidak memiliki pengaruh yang kuat pada kepercayaan merek, namun komunikasi merek dapat memiliki pengaruh kepercayaan merek dan loyalitas merek melalui citra merek. Komunikasi merek memiliki hubungan yang kuat dalam meningkatkan kesadaran dan citra merek.

\section{Kaitan antara Brand Image terhadap Brand Loyalty dengan Brand Trust sebagai Mediasi}

Menurut Muzammil et al. (2017) dalam penelitiannya menyatakan hasil bahwa citra perusahaan secara tidak langsung berpengaruh positif dan signifikan terhadap loyalitas pelanggan melalui kepercayaan pelanggan dengan $\beta=0,156$ dan t hitung $=3,008$, dengan uji sobel sebesar 3,034 yang menghasilkan $p$-value $=0,002$. Hal ini berarti citra merek memiliki pengaruh positif dan signifikan terhadap loyalitas merek melalui kepercyaan merek sebagai mediasi. Menurut Chinomona (2016) dalam penelitiannya menyatakan bahwa citra merek sangat kuat mempengaruhi hubungan brand trust dengan path coefficient sebesar 0,557 dan brand trust memiliki hubungan yang cukup kuat pula dengan loyalitas merek sebesar path coefficient 0,511 . Hal tersebut disebabkan bahwa pelanggan cenderung percaya dan menjadi setia kepada merek melalui citra merek. 
Berdasarkan pemaparan diatas, maka model dan hipotesis penelitian yang digunakan dalam penelitian ini adalah sebagai berikut.

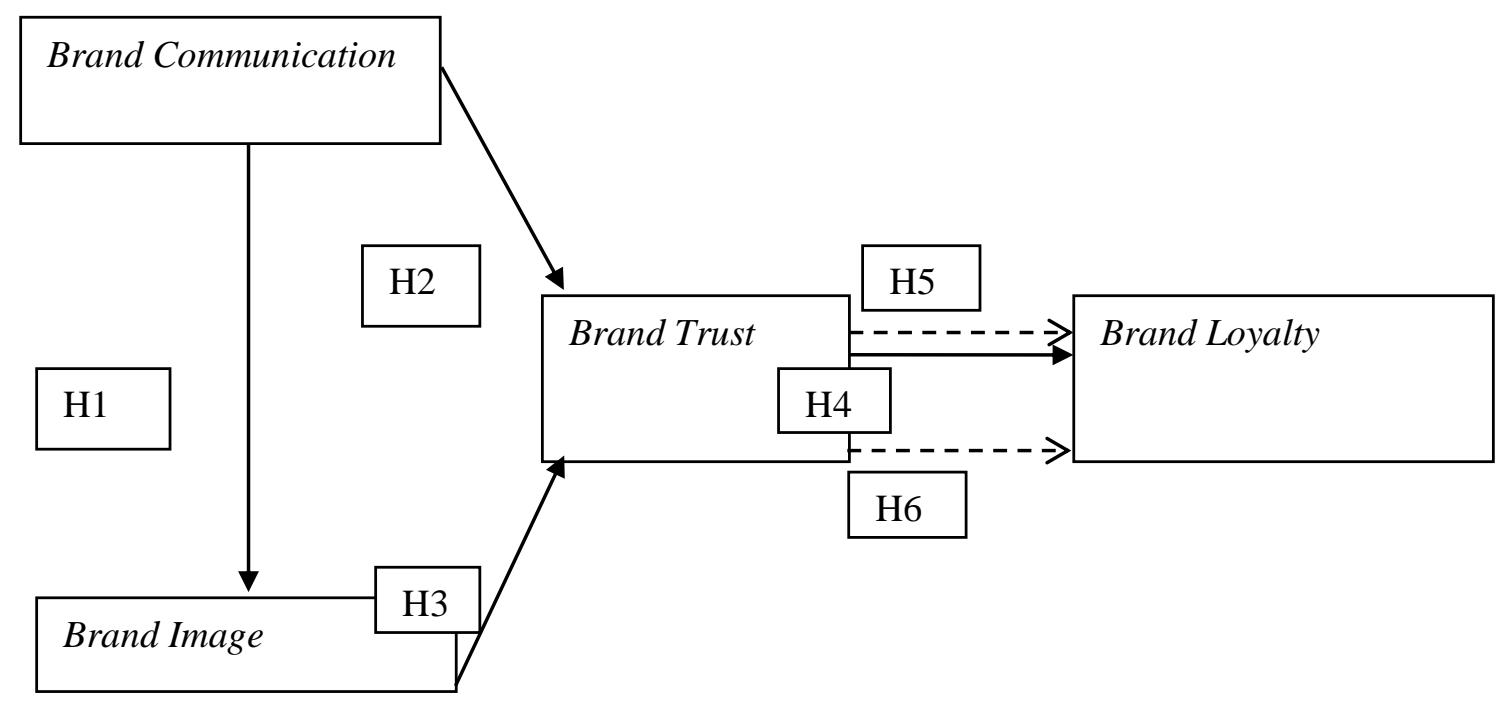

Gambar 1. Model Penelitian

$\mathrm{H} 1$ : brand communication memberikan pengaruh positif dan signifikan untuk brand image.

$\mathrm{H} 2$ : brand communication memberikan pengaruh positif dan signifikan untuk brand image.

H3 : brand image memberikan pengaruh positif dan signifikan untuk brand trust.

H4 : brand trust memberikan pengaruh positif dan signifikan untuk brand loyalty.

H5 : brand communication memberikan pengaruh positif dan signifikan terhadap brand loyalty melalui brand trust sebagai mediasi.

H6 : brand image memberikan pengaruh positif dan signifikan terhadap brand loyalty melalui brand trust sebagai mediasi.

\section{METODOLOGI}

Penelitian ini menggunakan desain penelitian deskriptif, dimana teknik pengambilan data dilakukan dengan cara purposive sampling yaitu dengan mempertimbangkan sumber data yang dianggap paling tahu terlebih dahulu tentang apa yang diharapkan. Penelitian ini menggunakan sampel sebanyak 100 orang konsumen H\&M di Jakarta untuk diminta menanggapi pernyataan dalam kuesioner yang disebarkan dalam bentuk google form, dimana data pernyataan-pernyataan diukur dengan skala Likert. Data pada penelitian ini diolah dengan metode structural equation model partial least square (PLS-SEM). 


\section{HASIL ANALISA DATA}

Subjek penelitian terdiri dari 51 responden berjenis kelamin perempuan, dan 49 responden berjenis kelamin laki-laki, dengan mayoritas responden berusia 18-21 tahun (54\%). Responden merupakan konsumen H\&M yang berdomisil di Jakarta, dengan mayoritas responden memiliki total pengeluaran per bulan di kisaran Rp 500.000 hingga Rp 1.499.999 juta. Analisa data menggunakan PLS-SEM. Penelitian ini memilih objek penelitian pada perusahaan retail fashion di Jakarta. Kuesioner disebarkan kepada konsumen H\&M di Jakarta dengan total 100 responden, dimana responden diminta untuk memberi tanggapan antara sangat tidak setuju (STS), tidak setuju (TS), netral (N), setuju (S), dan sangat setuju (SS) mengenai pernyataan dalam kuesioner terkait.

Tabel 1. Validitas dan Reliabilitas

\begin{tabular}{|l|l|l|}
\hline Variabel & CR & AVE \\
\hline Komunikasi Merek & 0,755 & 0,504 \\
\hline Citra Merek & 0,503 & 0,666 \\
\hline Kepercayaan Merek & 0,546 & 0,521 \\
\hline Loyalitas Merek & 0,732 & 0,556 \\
\hline
\end{tabular}

Menurut (Hair et al., 2017) menjelaskan bahwa composite reliability (CR) dianggap reliabel apabila memiliki nilai lebih besar dari 0,7, sehingga dapat disimpulkan bahwa ukuran pada penelitian ini dapat dianggap reliabel. Sedangakan untuk average variance extracted (AVE) (Hair et al., 2017) menyatakan bahwa nilai AVE harus lebih besar dari 0,5, sehingga dapat disimpulkan nilai AVE dianggap valid.

Tabel 2. Analisis Data

\begin{tabular}{|l|l|l|l|}
\hline & $\mathrm{R}^{2}$ & Adjusted $\mathrm{R}^{2}$ & $\mathrm{Q}^{2}$ \\
\hline BC & - & - & 0,249 \\
\hline BI & 0,119 & 0,110 & 0,072 \\
\hline BT & 0,315 & 0,301 & 0,085 \\
\hline BL & 0,332 & 0,311 & 0,264 \\
\hline
\end{tabular}

Menurut (Hair et al., 2017) menjelaskan bahwa nilai $\mathrm{R}^{2}$ bernilai 0 sampai 1, dimana semakin besar nilai tersebut maka semakin baik tingkat prediktif dari suatu model penelitian. (Hair et al., 2017) menyatakan bahwa nilai $\mathrm{Q}^{2}$ memiliki kemampuan prediktif yang relevan dimana apabila nilai $\mathrm{Q}^{2}$ lebih besar dari 0 . Dapat dilihat komunikasi merek dan loyalitas merek memiliki kemampuan prediktif lebih besar dari pada citra merek dan kepercayaan merek.

Pengujian Hipotesis. Pengujian Hipotesis dilakukan pada PLS-SEM dengan metode bootsrapping dimana nilai $\mathrm{p}$ harus lebih kecil dari 0,05 . 
Hasil pengujian hipotesis pertama menyatakan bahwa brand communication memiliki pengaruh yang positif dengan path coefficient sebesar 0,367 dan signifikan yakni $\mathrm{p}<0,05$ terhadap brand image, dimana hal tersebut menyatakan bahwa $\mathrm{H}_{1}$ brand communication memiliki pengaruh positif terhadap brand image.

Hasil pengujian hipotesis kedua menyatakan bahwa brand communication memiliki pengaruh yang positif dengan path coefficient sebesar 0,236 dan signifikan yakni $\mathrm{p}<0,05$ terhadap brand trust, dimana hal tersebut menunjukan bahwa $\mathrm{H}_{2}$ brand communication memiliki pengaruh positif terhadap brand trust.

Hasil pengujian hipotesis ketiga menyatakan bahwa brand image memiliki pengaruh yang positif dengan path coefficient sebesar 0,344 dan signifikan yakni $\mathrm{p}<0,05$ terhadap brand trust, dimana hal tersebut menunjukan bahwa $\mathrm{H} 3$ brand image memiliki pengaruh yang positif terhadap brand trust.

Hasil pengujian hipotesis keempat menyatakan bahwa brand trust memiliki pengaruh yang positif dengan path coefficient sebesar 0,335 dan signifikan yakni $\mathrm{p}<0,05$ terhadap loyalitas merek, dimana hal tersebut menunjukan bahwa $\mathrm{H} 4$ brand trust memiliki pengaruh yang positif terhadap loyalitas merek.

Hasil pengujian hipotesis kelima menyatakan bahwa brand communication memiliki pengaruh yang negatif dengan path coefficient sebesar -0,099 dan tidak signifikan yakni $\mathrm{p}>$ 0,05 terhadap loyalitas merek, dimana hal tersebut menunjukan bahwa H5 brand communication memiliki pengaruh yang negatif terhadap loyalitas merek.

Hasil pengujian hipotesis keenam menyatakan bahwa brand image memiliki pengaruh yang positif dengan path coefficient sebesar 0,434 dan signifikan yakni $\mathrm{p}<0,05$ terhadap loyalitas merek, dimana hal tersebut menunjukan bahwa H6 brand image memiliki pengaruh yang positif terhadap loyalitas merek.

Tabel 3. Pengujian Hipotesis

\begin{tabular}{|l|l|l|l|}
\hline & Path Coefficient & P values & Kesimpulan \\
\hline $\mathrm{BC} \rightarrow \mathrm{BI}$ & 0,367 & 0,001 & H1 diterima \\
\hline $\mathrm{BC} \rightarrow \mathrm{BT}$ & 0,236 & 0,014 & H2 diterima \\
\hline $\mathrm{BI} \rightarrow \mathrm{BT}$ & 0,344 & 0,000 & $\mathrm{H}$ diterima \\
\hline $\mathrm{BT} \rightarrow \mathrm{BL}$ & 0,335 & 0,001 & $\mathrm{H} 4$ diterima \\
\hline $\mathrm{BC} \rightarrow \mathrm{BL}$ & $-0,099$ & 0,352 & $\mathrm{H}_{5}$ tidak diterima \\
\hline $\mathrm{BI} \rightarrow \mathrm{BL}$ & 0,434 & 0,000 & $\mathrm{H}_{6}$ diterima \\
\hline
\end{tabular}

\section{DISKUSI}

Berdasarkan hasil analisa data, dapat disimpulkan bahwa seluruh hipotesis pada penelitian ini menunjukan bahwa semakin baik komunikasi yang dilakukan suatu merek dan didukung oleh citra yang baik suatu merek berikan akan berdampak pada tingkat kepercayaan merek yang dimiliki konsumen, dimana hal tersebut akan berdampak langsung pada tingkat loyalitas konsumen merek tersebut. Berdasarkan hasil analisa data yang didapat, disimpulkan bahwa konsumen H\&M di Jakarta mayoritas memilih citra merek merupakan aspek paling penting dalam hal menciptakan loyalitas merek konsumen. Semakin berkembangnya jaman semakin ketat pula persaingan bisnis yang sudah terjun ke arah digital atau e-commerce. 
Dalam hal ini perusahaan H\&M, walaupun citra merek H\&M sudah baik, tetapi perubahan keputusan pembelian konsumen dalam menggunakan merek mempengaruhi kepercayaan merek saat menggunakan merek tersebut, dalam hal ini perusahaan H\&M. Oleh sebab itu, dapat diambil kesimpulan bahwa konsumen di Jakarta tidak hanya mempercayai citra merek melainkan komunikasi merek untuk mempercayaai suatu merek dalam menggunakan merek, dalam hal ini kosumen H\&M di Jakarta sehingga konsumen dapat memutuskan untuk setia terhadap merek tersebut.

\section{PENUTUP}

Berdasarkan kesimpulan diambil pada penelitian ini, penting bagi $\mathrm{H} \& \mathrm{M}$ untuk terus meningkatkan komunikasi mereknya dan citra mereknya secara konsisten agar konsumen percaya lalu setia saat menggunakan merek tersebut. Untuk membangun loyalitas merek yang kuat, diperlukan pengaruh variabel-variabel lain yang sayangnya, karena keterbatasan peneliti, variabel-variabel lain tidak terdapat penelitian ini. Untuk itu diperlukan penelitian lebih lanjut mengenai faktor-faktor yang mempengaruhi konsumen dalam mengambil keputusan untuk setia terhadap suatu merek.

\section{DAFTAR PUSTAKA}

Ahmed, Z. (2014). Effect of Brand Trust and Customer Satisfaction on Brand Loyalty in Bahawalpur. Journal of Sociological Research, 5(1), 306-326.

Ahsan, O. B. (2019). Dimension of brand communcation, image and trust as antecedents of brand loyalty. Journal of Marketing and Logistics, 1, 31-49.

Alhaddad, A. (2015). The Relationships between Brand Image, Brand Trust and Brand Loyalty. International Journal of Management Research \& Review, 5(3), 137-144.

Arenggoasih, W. (2016). Pengaruh brand communication, service quality dan trust terhadap brand loyalty dewan pemilih. Jurnal Ilmu Komunikasi, 5(2), 123-135.

Azjen, I. (1991). The Theory of Planned Behavior. Organizational Behavior and Human Decision Processes, 50(2), 197-211.

Ballester, I.E.D. and Aleman, M.J.L. (2001). Brand Trust in the Context of Consumer Loyalty. European Journal of Marketing, 35(11/12), 1238-1258.

Chinomona, R. (2016). Brand Communication, Brand Image and Brand Trust as Antecedents of Brand Loyalty. Africa Journal of Economy and Management Studies, 7(1), 129-139.

Cretu, A.E. and Brodie, R.J. (2007), "The influence of brand image and company reputation where manufacturers market to small firms: a customer value perspective", Industrial Marketing Management, Vol. 36 No. 2, pp. 230-240.

Delgado, E; Munuera-Aleman, J, L; \& Yague, M, J. (2003). Development and Validation of a Brand Trust Scale. International Journal of Marketing Research, 45(1), 35-54

Hair, J. F., Hult, G. T. M., Ringle, C. M., \& Sarstedt, M. (2017). A Primer on Partial Least Square Structural Equation Modeling (PLS-SEM). $2^{\text {nd }}$ Edition. Los Angeles: Sage

Kotler, Phillip, (2003), Marketing Management. 12th Edition. New Jersey: Pearson.

Low, G.S. and Lamb, C.W.J. (2000). The Measurement and Dimensionality of Brand Associations. The Journal of Product and Brand Management, 9(6), 350-368

Muzammil, A., Yunus, M., \& Darsono, N. (2017). Kualitas pelayanan dan citra terhadap loyalitas pelanggan indihome di banda aceh. Journal Manajemen dan Inovasi. 8(3). 104-133.

Pertiwi, A. R., Djawahir, A. H., \& Andarwati. (2017). Pengaruh brand experience terhadap brand satisfaction, brand trust dan brand loyalty. Journal Manajemen, 5(2). 20-35. 
Ramdhani, Z. S. \& Widodo, T. (2019). Pengaruh komunikasi, citra dan kepercayaan terhadap loyalitas merek smartphone lenovo. e-Proceeding of Management, Vol.6, No.3, 56195626

Revanto, R. A. (2016). Pengaruh persepsi konsumen terhadap brand trust pada brand smartfren di kota Surabaya. Skripsi Fakultas Ilmu Sosial dan Ilmu Politik. Universitas Brawijaya, Malang.

Rika, O., Suddin, A., \& Widajandi, E. (2020). loyalitas merek dilihat dari komunikasi merek melalui kepercayaan merek sebagai pemediasi. Journal Manajemen Sumber Daya Manusia, 13(1), 52-67.

Sahin, A., Zehir, C. And Kitspci, H. (2011). "Relationships among brand idenity, brand image and brand preference: differences between cyber and extension retail brand over time", Journal of Interactive Marketing, Vol. 25 No. 3, pp. 169-177.

Salinas, E.M. and Perez, J.M.P (2009). "Modeling the brand extension' influence on brand image", Journal of Business Research, Vol.62 No. 1, pp. 50-60.

Sayekti, W., Syah, T. Y. R., \& Negoro, D. A. (2019). The effect of brand communication, image, and trust on brand loyalty. International Journal of Economics, Commerce and Management, 7(2019), 64-76.

Sekaran, U \& Bougie, R. (2013). Research Methods for Business. $6^{\text {th }}$ edition. John Wiley \& Sons Ltd

Sumarwan, U. (2011) Perilaku konsumen teori dan penerapannya dalam pemasaran. Bogor, ID: Ghalia Indonesia.

Susilawati, W. \& Wufron. (2017). Pengaruh brand image terhadap brand trust serta impilkasinya terhadap brand loyalty. Journal Wacana Ekonomi, 17(1). 24-34.

Toha, Jessica. (2016). Pengaruh brand communication dan brand image terhadap brand trust semen tiga roda. Jurnal Strategi Pemasaran, 3(2), 1-8.

Zehir, C., Sahin, A., Kitapci, H., \& Ozsahin, M. (2011). The effect of brand communication in brand loyalty through brand trust. The Journal of Procedia and Behavioral Sciences, 24(2011),1218-1231 